\title{
Physicochemical and dissolution profile characterization of pellets containing different binders obtained by the extrusion- spheronization process
}

\author{
Michele Georges Issa, Letícia Pessole, Andrea Ikeda Takahashi, Newton Andréo Filho, \\ Humberto Gomes Ferraz*
}

Department of Pharmacy, Faculty of Pharmaceutical Sciences, University of São Paulo

\begin{abstract}
With the purpose of evaluating the behavior of different polymers employed as binders in small-diameter pellets for oral administration, we prepared formulations containing paracetamol and one of the following polymers: PVP, PEG 1500, hydroxypropylmethylcellulose and methylcellulose, and we evaluated their different binding properties. The pellets were obtained by the extrusion/spheronization process and were subsequently subjected to fluid bed drying. In order to assess drug delivery, the United States Pharmacopeia (USP) apparatus 3 (Bio-Dis) was employed, in conjunction with the method described by the same pharmacopeia for the dissolution of paracetamol tablets (apparatus 1). The pellets were also evaluated for granulometry, friability, true density and drug content. The results indicate that the different binders used are capable of affecting production in different ways, and some of the physicochemical characteristics of the pellets, as well as the dissolution test, revealed that the formulations acted like immediate-release products. The pellets obtained presented favorable release characteristics for orally disintegrating tablets. USP apparatus 3 seems to be more adequate for discriminating among formulations than the basket method.
\end{abstract}

Uniterms: Binders/evaluation. Pellets/dissolution profile. Pellets/physicochemical characteristics. Extrusion/spheronization process. Drug delivery/evaluation.

Com a finalidade de se avaliar o comportamento de diferentes polímeros empregados como aglutinantes em pellets de pequeno diâmetro para uso oral foram preparadas formulações contendo paracetamol e um dos seguintes polímeros: PVP, PEG 1500, hidroxipropilmetilcelulose e metilcelulose por apresentarem diferentes propriedades aglutinantes. Os pellets foram obtidos pelo processo de extrusão/esferonização e secagem em leito fluidizado. Para avaliar a liberação do fármaco, empregou-se o método 3 da Farmacopeia Americana, também conhecido como Bio-Dis e o método preconizado pela mesma farmacopeia para comprimidos de paracetamol. Os pellets foram avaliados, ainda, com relação à granulometria, friabilidade, densidade verdadeira e teor. Os resultados indicaram que os diferentes aglutinantes empregados são capazes de afetar a produção e algumas das características físico-químicas dos pellets e o ensaio de dissolução revelou que as formulações comportam-se como produtos de liberação imediata. Os pellets obtidos apresentaram características de liberação favoráveis para a obtenção de comprimidos de liberação instantânea. O aparato 3 da Farmacopeia Americana demonstrou ser um método com melhor capacidade discriminatória entre as formulações, quando comparado com o método da cesta.

Unitermos: Aglutinantes/avaliação. Pellets/perfil de dissolução. Pellets/características físico-químicas. Processo de extrusão/esferonização. Liberação do fármaco.

\section{INTRODUCTION}

In recent years, the cost of developing new drugs has

\footnotetext{
*Correspondence: H.G. Ferraz. Department of Pharmacy, Faculty of Pharmaceutical Sciences, University of São Paulo. Rua do Lago, 250 - Prédio SemiIndustrial - Térreo - Cidade Universitária - Butantã - 05508-080 - São Paulo - SP, Brazil. Tel.: +55 11 3091-8954. E-mail: sferraz@usp.br
}

become a significant hurdle for the pharmaceutical industry, such that innovative product launches are increasingly rare. In an attempt to address this issue, research into new systems capable of more efficient delivery of dosage forms already widely-used in treatment processes is on the increase (Mahato, 2007; Qiu et al., 2009).

Accordingly, technologies that promote controlled 
drug delivery via oral route have increasingly been the subject of pharmaceutical research, thus fairly consistently fulfilling the necessities of clinical medicine by promoting improvements in bioavailability, with extended action and reduced toxic side-effects (Pezzini, Silva, Ferraz, 2007; Qiu et al., 2009).

Among the different systems/technologies available are the so-called pellets, also known as micro-granules, which are spherical structures of varying diameters used for drug delivery via oral route. They present several technological advantages compared to other dosage forms, including improved flowability properties, greater resistance to abrasion (friability) and ease of coating, etc. (GhebreSellassie, 1989; Santos et al., 2002; Pund et al., 2010).

Pellets can be obtained by means of several different processes, of which extrusion followed by spheronization and fluid bed drying is the most common. Pellets produced in this manner are suitable for coating, and this is the most widely-recommended process for producing a modified release, multi-particulate dosage form (Ghebre-Sellassie, 1989; Costa et al., 2003; Costa, Pais, Sousa, 2004; Santos et al., 2002; Pund et al., 2010).

Moreover, dissolution testing of solid dosage forms is a very useful resource for developing these formulations, since it is an in vitro system capable of predicting the release behavior of a dosage form (Costa et al., 2003; Doukoumetzidis, Macheras, 2006; Azarmi, Roa, Löbenberg, 2007).

For controlled release dosage forms, the device designated by the United States Pharmacopeia as apparatus 3 , also known as "reciprocating cylinders" or Bio-Dis, stands out, especially for its ability to subject formulations to different $\mathrm{pH}$ conditions, thus simulating their passage through the human gastrointestinal tract (Klein, Rudolph, Dressman, 2002; Yu, Wang, Hussain, 2002; Krämer, Grady, Gajendran, 2005).

In order to obtain a controlled-release dosage form, the use of agents (excipients) capable of influencing drug delivery is essential, thus enabling the acquisition of adequate blood levels for extended periods of time, compared to conventional dosage forms (Mahato, 2007).

Accordingly, prior knowledge of the behavior of these materials (in general polymers) is useful for predicting the release profile that they will produce, especially considering the dynamics of the gastrointestinal tract, which subjects the dosage form to different $\mathrm{pH}$ conditions at different points in its trajectory.

Regardless of the desired release profile for a particular drug incorporated into a certain pellet formulation, the binder is, without a doubt, one of the main components of this dosage form. The success of a formulation of this type largely depends on this excipient, since a pellet is precisely a spherical agglomeration of powders. Therefore, the binder will be responsible for pellet integrity and may also influence the manufacturing process, dissolution, physical stability, among others. (Ghebre-Sellassie, 1989).

Moreover, pellets may be an interesting alternative for producing orally disintegrating tablets (ODTs). These solid dosage forms are designed to rapidly disintegrate in the mouth when in contact with saliva, thus not requiring water for administration. A strategy to mask drug taste, without causing any modification in drug release, is necessary. Paracetamol is an analgesic drug and its administration in ODT form could be applicable in pediatric treatment for acute pain, as an alternative to liquid dosage forms (AlHusban, Perrie, Mohammed, 2011).

The purpose of this study was to evaluate the impact of the use of different binders in the manufacture of small-diameter pellets containing paracetamol by means of physicochemical characterization of the formulations and an assessment of their dissolution profile by means of two different tests employing apparatuses 1 and 3 from the United States Pharmacopeia.

\section{MATERIAL AND METHODS}

\section{Raw material}

All raw material used was of pharmaceutical grade and it was used as received. The paracetamol was kindly donated by Medley S.A. Indústria Farmacêutica.

The type-101 microcrystalline cellulose, commercially designated Microcel MC101 ${ }^{\circledR}$, and the type 2208 hydroxypropylmethylcellulose (HPMC) (USP 32), com-

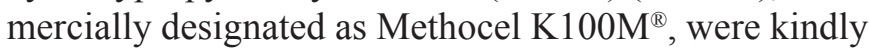
donated by Colorcon do Brasil Ltda.

\section{Formulations}

Four formulations, each with a different binder, were prepared, as indicated in Table I.

The concentrations of binders we selected were those commonly used in our laboratory.

The following procedure was adopted for pellet production: after being weighed, the paracetamol and the microcrystalline cellulose were mixed in a household mixer $( \pm 20 \mathrm{rpm})$ for around 10 minutes. Then the previously prepared binder solution was added, little by little, and homogenization was continued until the mass reached the point where it could be extruded; this was ascertained visually. The material was then placed in an APEX ${ }^{\circledR}$ Multiplex DUA-11 (New Jersey, USA) radial-type extruder, 
TABLE I - Qualitative and quantitative composition of the pellet formulations produced

\begin{tabular}{lcccc}
\hline COMPONENT & $\mathbf{1}$ & $\mathbf{2}$ & $\mathbf{3}$ & $\mathbf{4}$ \\
\hline Paracetamol (\%) & 70 & 70 & 70 & 70 \\
mass (g) & 140 & 140 & 140 & 140 \\
Microcrystalline cellulose (\%) & 30 & 30 & 30 & 30 \\
mass (g) & 60 & 60 & 60 & 60 \\
PVP K-30* (g) & 100.51 & --- & --- & --- \\
PEG 1500*(g) & --- & 94.78 & --- & --- \\
HPMC* (g) & --- & --- & 37.13 & --- \\
Methylcellulose* (g) & --- & --- & --- & 69.16 \\
Water (g) & --- & --- & 37.39 & 4.23 \\
\hline
\end{tabular}

*In solution form or dissolved in water at $5 \%$

set to $\pm 3 \mathrm{rpm}$ and fixed with a $0.5 \mathrm{~mm}$ mesh. The extruded material was then transferred to a CALEVA ${ }^{\circledR}$ Model 250 spheronizer (Dorset, UK), equipped with a "cross-hatch" plate, rotating at 1,000 rpm for about 4 minutes. The pellets were then dried in a HÜTTLIN ${ }^{\circledR}$ Mycrolab fluid bed (Steinen, Germany) for 40 minutes, with an input air temperature of $55^{\circ} \mathrm{C}$, at a flow rate of $12 \mathrm{~m}^{3}$ per hour.

The process yield was evaluated by comparing the theoretical value (the sum of the formulation components, except water) with the number of pellets obtained.

\section{Evaluation of the pellets obtained}

\section{Granulometry}

The batches were granulometrically classified in a Haver \& Bocker EML Digital Plus test sieve shaker (Westfalen, Germany), with an amplitude of 1.0, a stirring time of 2 minutes, a 10 -second interval between pulses and previously tared test sieves with $0.80,0.71$, $0.59,0.42,0.297,0.250,0.210,0.180$ meshes and a collecting pan. After classification, the test sieves were weighed separately in order to ascertain whether any mass was retained in them.

\section{Friability}

About $10 \mathrm{~g}$ of pellets were weighed and then were placed into a Haver \& Bocker EML Digital Plus mechanical test sieve shaker (Westfalen, Germany), operating under the same conditions as the granulometry assay. After the pellets were classified, the material was gathered up and placed in a Logan ${ }^{\circledR}$ FAB-2 friability tester (Somerset, USA), together with 200 glass spheres measuring $4.3 \mathrm{~mm}$ in diameter. The assay time was 8 minutes, totaling 200 rotations. Then the pellets were removed and again subjected to another granulometric assay. Besides post-assay granulometry comparison, the percentage of powder withheld in the collecting pan was also calculated.

\section{True Density}

After weighing about $3 \mathrm{~g}$ of pellets directly in the sample recipient, which was filled to half way, the material was transferred to a Quantachrom Instruments ${ }^{\circledR}$ Ultrapycnometer 1000 gas pycnometer (Boynton Beach, USA).

\section{Morphological Analysis}

Images were obtained for each batch using a Fuji Film Fine Pix S5100 ${ }^{\circledR}$ camera coupled to a Motic SMZ $168^{\circledR}$ stereomicroscope, set to $10 \mathrm{x}$ magnification. These images were then edited with the Image Pro-Plus ${ }^{\circledR}$ version 4.5.0.29 software program, from which the average diameter, aspect and sphericity parameters were calculated. For calibration purposes, an image (obtained under the same conditions) of a standard slide containing a straight $1 \mathrm{~cm}$ segment, with 100 divisions, was employed.

\section{Paracetamol content}

In order to quantify the paracetamol contained in the pellets, a spectrophotometer was used in the UV, in accordance with the following procedure: one sample of each pellet formulation was ground up using a porcelain mortar and pestle, and from this resulting powder, about $100 \mathrm{mg}$ was weighed and then placed in a $100 \mathrm{~mL}$ volumetric flask.

Water was added and the flasks were placed in an ultrasonic cleaner for 10 minutes. The contents were then filtered through a $35 \mu \mathrm{m}$ Logan 200-1035 filter (Somerset, USA). An aliquot of the filtered material was diluted 200 times and the resulting solution was placed in a $0.5 \mathrm{~cm}$ quartz cuvette, and then in a Beckman Coulter DU $640^{\circledR}$ spectrophotometer, where a wavelength reading of $242.5 \mathrm{~nm}$ was attained. 


\section{Dissolution}

\section{Bio-Dis}

In order to evaluate the dissolution profile of the formulations, apparatus 3 from the United States Pharmacopeia, also known as Bio-Dis, was employed. The equipment (Varian Inc., Cary, USA) was configured to operate at a temperature of $37^{\circ} \mathrm{C}$ with $250 \mathrm{~mL}$ of dissolution medium, coupled to a Varian VK 8000 Dissolution Sampling Station (Cary, USA), programmed to collect a volume of $5 \mathrm{~mL}$ of the medium, at pre-established time intervals.

Initially, the pellets were dissolved in a $\mathrm{pH} 7.2$ phosphate buffer and then in $\mathrm{HCl} 0.1 \mathrm{~N}$, since these are used in the production of ODT. In this case, the first stage ( $\mathrm{pH}$ 7.2 phosphate buffer) is used to simulate the conditions encountered by the formulation in the mouth cavity, where drug release needs to be minimal (in order to avoid the unpleasant taste of the product), and in the second stage $(\mathrm{HCl} 0.1 \mathrm{~N})$, the drug needs to be released as fast as possible, in order to ensure its rapid absorption.

- $\quad$ Phosphate buffer pH 7.2 - used in the first row of vessels as an initial dissolution medium, with collection times programmed for 2 and 5 minutes and the device operating at 4 oscillations per minute (OPM); - Hydrochloric acid $0.1 \mathrm{~N}(\mathrm{HCl} 0.1 \mathrm{~N})$ - used in the second row of vessels, as the stage following the phosphate buffer medium, with collection times at $10,15,20,30$ and 45 minutes. In this medium, the stirring speed was 10 oscillations per minute.

After weighing (about $100 \mathrm{mg}$ of each formulation), the pellets were transferred to the cylinders of the device (fitted with a 1.25/177 $\mu \mathrm{m}$ "Poly screen") and then the assay was initiated, whereby the cylinders at 4 OPM were immersed in the phosphate buffer for 5 minutes. After this time, in accordance with the stipulated programming of the device, the cylinders were automatically transferred to operate at 10 OPM in the second row of vessels, containing the acid medium, for the next 40 minutes. The samples were quantified with a Beckman Coulter DU 640 spectrophotometer in a $0.5 \mathrm{~cm}$ cuvette at $242.5 \mathrm{~nm}$. Besides the dissolved percentage values used to obtain the dissolution profiles, the respective dissolution efficiency (DE) values were also calculated, in the manner described by Khan \& Rhodes (1975).

\section{Dissolution profile (apparatus 1 - basket)}

A dissolution profile for the formulations in a phosphate buffer $\mathrm{pH} 5.8$ was traced, as specified by USP 32 for paracetamol tablets, using a VanKel VK 7010 (Cary, USA) automated device coupled to a Varian Cary 50 spectropho- tometer (Cary, USA). As described in the United States Pharmacopeia, $900 \mathrm{~mL}$ of medium was employed, at a temperature of $37^{\circ} \mathrm{C}$, a stirring speed of $75 \mathrm{rpm}$ and collection times programmed for 2, 5, 10, 15, 20 and 45 minutes.

\section{RESULTS AND DISCUSSION}

The technology for obtaining pellets by means of the extrusion-spheronization process is, among other factors, fairly dependent on the excipients employed in the formulation, with emphasis on the binder. In fact, pellets are agglomerates of powders, which are united precisely by the action of these excipients and, therefore, the search for an adequate binder for a particular formulation is extremely important for the success of the product that is to be obtained (Ghebe-Sallassie, 1989; Wlosnewski, Kumpugdee-Vollrath, Sriamornsak, 2010).

Accordingly, four different binders dissolved in water were tested in this study and the following yield values were obtained: $74.39 \%, 67.05 \%$ and $81.73 \%$ and $63.22 \%$ for formulations $1,2,3$ and 4 , respectively.

These results, all less than $82 \%$ are, in fact, due largely to two main factors: (a) losses that occurred during extrusion in the APEX ${ }^{\circledR}$ device that, because of its design, ended up retaining a considerable quantity of mass that should have been extruded; and (b) the small size of the batches produced (200 g). The greater the quantity produced, the greater the yield, because the quantity of mass retained in the extruder is always the same, regardless of the volume of material processed. Therefore, we considered it improbable that the differences registered were due to the use of different binders.

In Figure 1, the granulometric distribution of the pellets obtained is shown, where it is possible to ascertain that, when PEG 1500 was used as a binder, there was practically no pellet formation, with a considerable amount of the material withheld at the bottom of the set of cloth filters. In contrast, the use of PVP resulted in larger and not very homogeneous pellets.

Considering this parameter, the best results were obtained with the use of methylcellulose (MC) and HPMC and, in both cases, there was a concentration of pellets in the $0.42 \mathrm{~mm}$ range. Methylcellulose is especially deserving of note, because more than $80 \%$ of it was retained in the $0.42 \mathrm{~mm}$ cloth filter.

With regards to friability, the results obtained (Figure 2) indicate that the pellets in which PVP was used as a binder were those in which the smallest alteration in granulometry was observed after the friability test, thus resulting in stronger pellets. For methylcellulose, there 


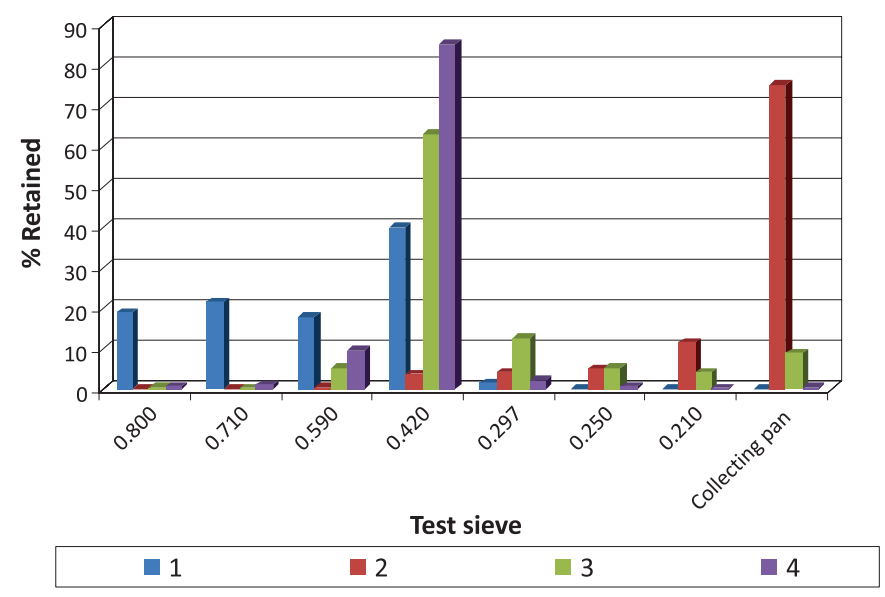

FIGURE 1 - Granulometric distribution of the pellets obtained using PVP (1), PEG 1500 (2), HPMC (3) and MC (4) as binders.

was a slight increase in the percentage retained in the 0.42 $\mathrm{mm}$ test sieve, and for the formulation in which HPMC was used, there was a greater increase in the percentage retained in the same test sieve. However, there was no powder formation in any of the three cases, as can be ascertained by the quantity of material retained in the collecting pan of the test sieve set.

It is important to emphasize that the method em- ployed here to evaluate pellet friability differs from that normally used and described in literature (Sousa et al., 2002; Cheboyina, Wyandt, 2008), since a change in the granulometry of each formulation has been considered. Accordingly, data has been obtained that enables a more wide-ranging evaluation of pellet behavior, taking into account the wear that the latter may be subject to.

Once density is established, obtained by means of a gas pycnometer, it also becomes a very important parameter in pellet production technology. Density is also a means of differentiating pellets from granules, since the latter are not subject to densification (by extrusion), contrary to pellets, which, generally speaking, have greater density. The results (presented in Table II and Figure 3) indicate that the type of binder employed in the formulation is capable of causing considerable modifications to pellet density, since the values obtained were found to be in the range from 1.4199 for the lowest (pellets with MC) to 1.4595 (PEG) for the highest value.

Although granulometric analysis is an excellent alternative for evaluating pellet size, visualizing the particles with the aid of a microscope is, without a doubt, the best alternative for studying pellet morphology. Accordingly, it is possible to ascertain not only measurements for the
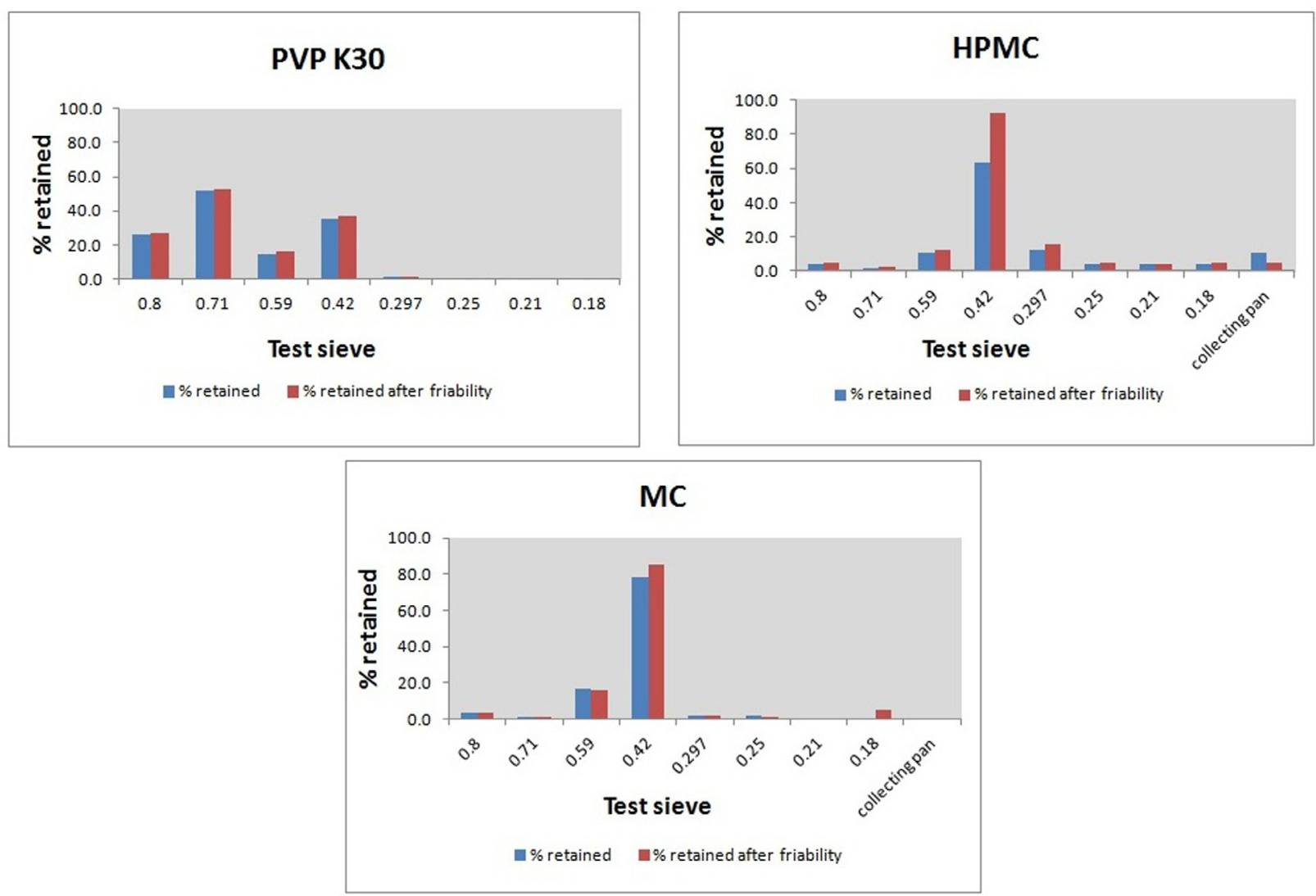

FIGURE 2 - Granulometric analysis of pellets 1 (PVP K30), 3 (HPMC) and 4 (MC) before and after the friability test. 
TABLE II - True density values obtained for the formulations produced. SD: standard deviation

\begin{tabular}{cccccc}
\hline Formulation & Sample 1 & Sample 2 & Sample 3 & Average & SD \\
\hline 1 & 1.4275 & 1.4270 & 1.4298 & 1.4281 & 0.00149 \\
2 & 1.4577 & 1.4595 & 1.4579 & 1.4584 & 0.00098 \\
3 & 1.4460 & 1.4438 & 1.4435 & 1.4444 & 0.00136 \\
4 & 1.4199 & 1.4174 & 1.4187 & 1.4187 & 0.00125 \\
\hline
\end{tabular}

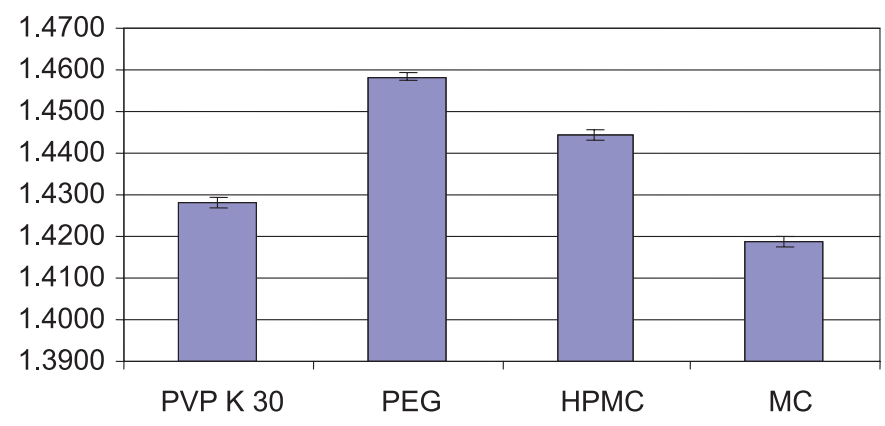

FIGURE 3 - Graphic representation of the true density values obtained for formulations 1 (PVP K30), 2 (PEG), 3 (HPMC) and 4 (MC). The bars indicate the respective standard deviations.

pellets formed, but also their shape (Abbaspour, Sadeghi, Afrasiabi, Garekani, 2008).

One quite interesting alternative is to use imageediting software with the capacity to calculate parameters pertaining to the shape of the particle under analysis. In this study, we used the Image Pro Plus ${ }^{\circledR}$ program, which enables, among other parameters, the average diameter and sphericity of the pellets to be calculated.

Analysis of these results (Table III) proves that the pellets are not perfectly spherical. According to Podczeck, Rahman, Newton (1999), a pellet should present values of 1.0 for aspect and up to 1.1 for sphericity. Chopra et al. (2002) considers that this value may reach up to 1.2. None of the formulations studied here conformed to these values, and results of more than 1.2 were obtained for both parameters.

Similarly, the average pellet diameter varied considerably, with the smallest particles being obtained for PEG, with a diameter of $0.1275 \mathrm{~mm}$, and up to 0.7286 for pellets containing MC. For this latter parameter, a value of close to $0.5 \mathrm{~mm}$ was expected, since a screen with this size opening was used with the extrusion device to produce these pellets.

This difficulty in obtaining spherical pellets, with a diameter close to that of the extruder screen, may be explained by two factors:

(a) the reduced size of the pellets: the production of dosage forms with reduced sizes is a challenge under any circumstances; (b) the elevated drug content (theoretically $70 \%$ ) in the pellets: microcrystalline cellulose, a component of fundamental importance in the production of pellets, because of its plasticity, is quite adequate for pellet production (Sousa et al., 2002; Sreie et al., 2005); however, in the formulations proposed here, this component is significantly diluted, as a result of the necessity to obtain pellets with a high drug concentration.

It is also necessary to consider that these two factors may have had a joint influence; in other words, the sum of two unfavorable conditions may have made the attainment of pellets with a suitable aspect even more difficult.

Therefore, it was ascertained that, in fact, the morphology of the pellets was significantly influenced by the type of binder used. The formulations containing PEG and $\mathrm{MC}$ are at both extremes, since very small pellets, or even powder (average diameter only $0.1275 \mathrm{~mm}$ ), were obtained with the former, while very large pellets, actually "rod-shaped" $(0.7286 \mathrm{~mm})$, were obtained with the latter. Both are the result of "weak" and very intensive flocculation, respectively, thus preventing separation of the pellets that form during spheronization and resulting in the "rod shapes".

Thus, upon analyzing such observations, we can state that PVP and HPMC are the binders with the greatest potential in the formulations studied herein.

Considering the paracetamol content found in the pellets (Table IV), it is possible to make adjustments to the quantities of pellets that are to be subjected to the dissolution test, thus correcting any distortions that may lead to erroneous interpretations with regards to this important assay.

One of the dissolution tests executed in this study, using apparatus 3 from the United States Pharmacopeia, was conceived in order to evaluate the dissolution profile of the pellets under changing $\mathrm{pH}$ conditions. Although the objective of our study was not the attainment of immediate release tablets, we cannot disregard the potential of these formulations; in other words, small-diameter pellets for this type of dosage form. In fact, the production of pel- 
TABLE III - Values for average diameter, aspect and sphericity obtained after editing images using the Image Pro Plus ${ }^{\circledR}$ software program, for the formulations containing PVP (1), PEG (2), HPMC (3) and MC (4). SD = standard deviation

\begin{tabular}{lcccc}
\hline Parameter & $\mathbf{1}$ & $\mathbf{2}$ & $\mathbf{3}$ & $\mathbf{4}$ \\
\hline Average diameter & 0.7232 & 0.1275 & 0.3282 & 0.7286 \\
\pm SD & 0.1820 & 0.0354 & 0.1023 & 0.1587 \\
Aspect & 1.2390 & 1.7182 & 1.4961 & 2.0833 \\
\pm SD & 0.0954 & 0.3709 & 0.2103 & 0.8802 \\
Sphericity & 1.4244 & 1.2274 & 1.3440 & 1.5441 \\
\pm SD & 0.2002 & 0.1093 & 0.1886 & 0.2435 \\
\hline
\end{tabular}

TABLE IV - Paracetamol content (\%), considering the theoretical drug value (70\%) added to formulations containing PVP (1), PEG (2), HPMC (3) and MC (4)

\begin{tabular}{lllll}
\hline & 1 & 2 & 3 & 4 \\
\hline 1 & 56.61 & 63.77 & 67.09 & 55.14 \\
2 & 59.97 & 60.64 & 67.67 & 58.53 \\
3 & 57.06 & 62.04 & 66.13 & 60.38 \\
Average & 57.88 & 62.15 & 66.96 & 58.02 \\
\hline
\end{tabular}

lets is only justifiable in the event that we wish to obtain a product with controlled (or modified) release, because otherwise the production of traditional tablets would be the most rational route to follow, considering the costs involved.

Thus, the dissolution profile of the pellets was traced under similar conditions to those found for an immediate release tablet when administered in the organism. The tablet is placed in the oral cavity, and remains in this environment for around 20-30 seconds, when it completely disintegrates after being subject to the action of accumulated saliva, and the resulting suspension is ingested. Subsequently, the particles containing the drug are subject to the action of gastric acid in the patient's stomach.

Therefore, the formulation will be subject to the action of saliva, which has a $\mathrm{pH}$ of around 7.0 (Pedersen et al., 2002) for a short period of time, but with one important consideration: drug delivery, in this environment, must be minimal, or, at the very most, reduced. This is because many drugs, including paracetamol, have an unpleasant taste and their dissolution in the oral cavity may lead to rejection of the product on the part of the patient. Total drug delivery would be a disaster in terms of patient comfort, however, to some degree, the flavor produced in the oral cavity could be masked with the aid of sweeteners and flavorings - indispensible components in immediate release tablet formulations.

On the other hand, when it reaches the stomach (pH
1-3), the drug must be quickly delivered so that it can be absorbed. Under these conditions, the challenge to overcome is considerable: to formulate a product capable of retaining the drug at a $\mathrm{pH}$ of close to 7.0 and then, soon after, to promote its rapid delivery in an acidic $\mathrm{pH}$ environment.

It is exactly in this type of situation that Bio-Dis comes into its own, because it was designed specifically for tests in which a change in the $\mathrm{pH}$ of the medium is a reality (Yu, Wang, Hussain, 2002; Pezzini, Ferraz, 2009; Samaha, Shehayeb, Kyriacos, 2009). Thus, the use of a $\mathrm{pH}$ close to neutral for evaluating the initial minutes of dissolution, combined with a very low stirring speed (only 4 OPM) for a short period of time (5 minutes), followed by transposition to a acidic $\mathrm{pH}$ value with a higher stirring speed (10 OPM), is the precise basis for the aforementioned conditions.

The dissolution profile obtained in Bio-Dis (Figure 4) shows that the difference registered in the delivery of paracetamol among the evaluated pellets is small and, therefore, the binder used does not have any significant effect on dissolution, at least under the conditions employed in this study. On the other hand, what seems to have been decisive with regards to dissolution was the granulometry of the pellets, since the formulation containing PVP, which presented a DE of $69.11 \%$ (Table V) was exactly that in which the pellets obtained were the largest in size (Figure 1).

Granulometry was also the reason why the pellets obtained with PEG 1500 could not be evaluated, with regards to dissolution. In this case, as has already been discussed, there was considerable formation of powder (Figure 1), which made it unfeasible to maintain the particles in the cylinders of the dissolution equipment (in this case the Bio-Dis).

As the pellets were put through a screen for the precise purpose of retaining the dosage form inside the cylinder, these pellets were deposited at the bottom of the dissolution vat, which gave rise to two serious problems: (a) the pellets were not properly stirred to promote drug 
TABLE V - The dissolved percentage ( \pm standard-deviation) obtained for the formulations containing PVP (1), HPMC (3) and MC (4) and their respective dissolution efficiency values (DE), in Bio-Dis. $n=3$

\begin{tabular}{lccc}
\hline Time (min) & 1 & 3 & 4 \\
\hline 2 & $38.64 \pm 0.1189$ & $45.85 \pm 0.1285$ & $45.69 \pm 0.0422$ \\
5 & $67.37 \pm 0.1279$ & $70.65 \pm 0.0756$ & $75.27 \pm 0.0173$ \\
10 & $89.46 \pm 0.0250$ & $86.40 \pm 0.0743$ & $96.60 \pm 0.0374$ \\
15 & $100.05 \pm 0.0335$ & $95.39 \pm 0.0899$ & $106.89 \pm 0.0532$ \\
20 & $104.98 \pm 0.0628$ & $98.07 \pm 0.1546$ & $112.01 \pm 0.0144$ \\
30 & $108.07 \pm 0.0407$ & $98.01 \pm 0.1501$ & $113.86 \pm 0.0401$ \\
45 & $108.89 \pm 0.0461$ & $97.45 \pm 0.1556$ & $113.40 \pm 0.0483$ \\
DE (\%) & 69.11 & 73.86 & 73.34 \\
\hline
\end{tabular}

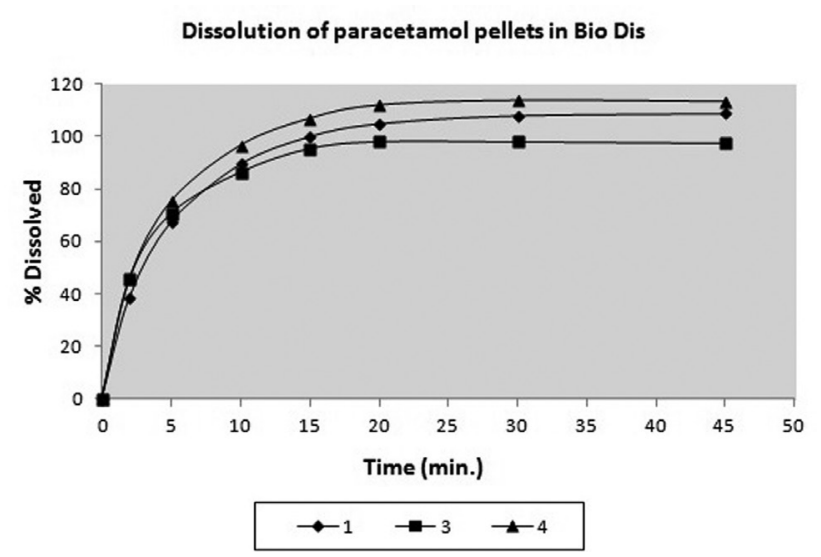

FIGURE 4 - Dissolution profiles obtained in Bio-Dis for formulations 1, 3 and 4. Media: up to 5 minutes - phosphate buffer $\mathrm{pH} 7.2$ and $\mathrm{HCl} 0.1 \mathrm{~N}$ added to the dissolution vat after 5 minutes. $\mathrm{n}=3$.

delivery; and (b) when the media were changed, the material remained in the previous vessel (in the phosphate buffer) and did not migrate together with the cylinders, to the acidic medium. Under these circumstances, a dissolution test involving the pellets in which PEG 1500 was used as a binder was unfeasible.
Regardless of the problem ascertained for the pellets with PEG, it was observed that the formulations containing PVP, HPMC and MC behaved like rapid-release formulations (more than $85 \%$ of the drug was released within 15 minutes), which, in fact, indicates the insignificant influence of the binders employed in our study.

Thus, when the purpose is to use such pellets to produce immediate release tablets, there is one more fundamentally important stage: coating, since adequate control over drug delivery is essential in this case.

The dissolution of the pellets obtained in the basket (apparatus 1), as proposed by USP 32 ed. (Table VI and Figure 5), indicated the same tendency as the profile obtained by means of the Bio-Dis: the formulations presented very close dissolution profiles. In fact, we observed that, with the basket, these values were even closer, almost superimposed, with a slight spread for pellets with PVP, between 10 and 20 minutes of dissolution.

\section{CONCLUSIONS}

From the results obtained in this study, it was ascertained that the use of different binders has a significant ef-

TABLE VI - Dissolved percentage ( \pm standard-deviation) obtained for each formulation and the respective dissolution efficiency values (DE) in apparatus 1 (basket). $\mathrm{n}=5$

\begin{tabular}{lccc}
\hline Time $(\mathrm{min})$ & 1 & 3 & 4 \\
\hline 2 & $20.32 \pm 0.0545$ & $24.14 \pm 0.0344$ & $21.28 \pm 0.0383$ \\
5 & $47.79 \pm 0.0721$ & $49.10 \pm 0.0594$ & $45.84 \pm 0.0404$ \\
10 & $68.27 \pm 0.0800$ & $71.86 \pm 0.0432$ & $70.80 \pm 0.0592$ \\
15 & $81.39 \pm 0.1184$ & $83.59 \pm 0.0483$ & $84.30 \pm 0.0635$ \\
20 & $87.56 \pm 0.1590$ & $89.89 \pm 0.0655$ & $90.27 \pm 0.0422$ \\
30 & $92.80 \pm 0.1502$ & $92.09 \pm 0.0896$ & $95.88 \pm 0.0549$ \\
45 & $90.93 \pm 0.0816$ & $90.14 \pm 0.0621$ & $100.49 \pm 0.0660$ \\
DE (\%) & 68.56 & 69.31 & 72.60 \\
\hline
\end{tabular}




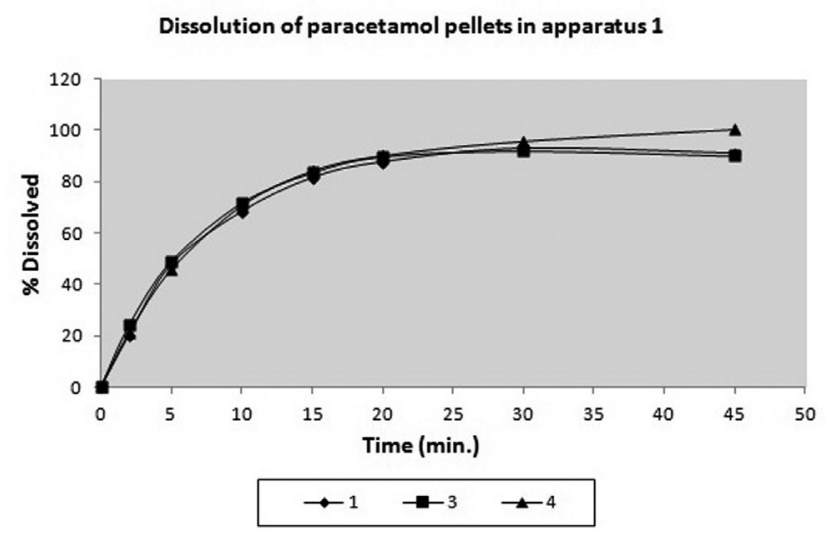

FIGURE 5 - Dissolution profiles obtained in apparatus 1 (basket) for formulations 1, 3 and 4. Medium: phosphate buffer $\mathrm{pH} 5.8$. $\mathrm{n}=5$.

fect on the production of small-diameter pellets containing paracetamol, as well as on some of their physicochemical characteristics, especially density. However, with regards to dissolution, evaluated by two different methods, the formulations all had immediate release characteristics. It was also ascertained that the dissolution test in Bio-Dis seems to be the most adequate for discriminating among formulations, when compared to the basket method.

\section{ACKNOWLEDGEMENTS}

The authors are grateful to FINEP (Financiadora de Estudos e Projetos) for their financial support.

\section{REFERENCES}

ABBASPOUR, M.R.; SADEGHI, F.; AFRASIABI GAREKANI, H. Design and study of ibuprofen disintegrating sustainedrelease tablets comprising coated pellets. Eur. J. Pharm. Biopharm., v.68, n.3, p.747-759, 2008.

ALHUSBAN, F.; PERRIE, Y.; MOHAMMED, A.R. Formulation of multiparticulate systems as lyophilized orally disintegrating tablets. Eur. J. Pharm. Biopharm., v.79, n.3, p.627-634, 2011.

AZARMI, S.; ROA, W.; LÖBENBERG, R. Current perspectives in dissolution testing of conventional and novel dosage forms. Int. J. Pharm., v.328, n.1, p.12-21, 2007.

CHEBOYINA, S.; WYANDT, C.M. Wax-based sustained release matrix pellets prepared by a novel freeze pelletization technique I. Formulation and process variables affecting pellet characteristics. Int. J. Pharm., v.359, n.1-2, p.158166, 2008.
CHOPRA, R.; ALDERBORN, G.; NEWTON, J.M.; PODCZECK, F. The influence of film coating on pellet properties. Pharm. Dev. Technol., v.7, n.1, p.59-68, 2002.

COSTA, F.O.; SOUSA, J.J.S.; PAIS, A.A.C.C.; FORMOSINHO, S.J. Comparison of dissolution profiles of Ibuprofen pellets. J. Control. Release, v.89, n.2, p.199-212, 2003.

COSTA, F.O.; PAIS, A.A.C.C.; SOUSA, J.J.S. Analysis of formulation effects in the dissolution of ibuprofen pellets. Int. J. Pharm., v.270, n.1-2, p.9-19, 2004.

DOUKOMETZIDIS, A.; MACHERAS, P. A century of dissolution research: from Noyes and Whitney to the Biopharmaceutics Classification System. Int. J. Pharm., v.321, n.1, p.1-11, 2006.

GHEBRE-SELLASSIE, I. Pharmaceutical pelletization technology. New York: Marcel Dekker, 1989. 274 p.

KHAN, K.A.; RHODES, C.T. The concept of dissolution efficiency. J. Pharm. Pharmacol., v.27, n.1, p.48-49, 1975.

KLEIN, S.; RUDOLPH, M.W.; DRESSMAN, J.B. Drug release characteristics of different mesalazine products using USP apparatus 3 to simulate passage through the GI tract. Dissolut. Technol., v.9, n.4, p.6-13, 2002.

KRÄMER, J.; GRADY, L.T.; GAJENDRAN, J. Historical development of dissolution tests on the basis of gastrointestinal physiology. In: DRESSMAN, J.; KRÄMER, J. (Eds.). Pharmaceutical dissolution testing. Boca Raton: Taylor \& Francis Group, 2005. 429 p.

MAHATO, R.I. Pharmaceutical dosage forms and drug delivery. Boca Raton: Taylor \& Francis Group, 2007.300 p.

PEDERSEN, A.M.; BARDOW, A.; JENSEN, S.B.; NAUNTOFTE, B. Saliva and gastrointestinal functions of taste, mastication, swallowing and digestion. Oral Dis., v.8, n.3, p.117-129, 2002.

PEZZINI, B.R.; SILVA, M.A.S.; FERRAZ, H.G. Formas farmacêuticas sólidas orais de liberação prolongada: sistemas monolíticos e multiparticulados. Braz. J. Pharm. Sci., v.43, n.4, p.491-502, 2007.

PEZZINI, B.R.; FERRAZ, H.G. Bio-Dis and the paddle dissolution apparatuses applied to the release characterization of ketoprofen from hypromellose matrices. AAPS PharmSciTech, v.10, n.3, p.763-771, 2009. 
PODEZECK, F.; RAHMAN, S.R.; NEWTON, J.M. Evaluation of a standardized procedure to assess the shape of pellets using image analysis. Int. J. Pharm., v.192, n.2, p.123-128, 1999.

PUND, S.; JOSHI, A.; VASU, K.; NIVSARKAR, M.; SHISHOO, C. Multivariate optimization of formulation and process variables influencing physic-mechanical characteristics of site-specific release isoniazid pellets. Int. J. Pharm., v.388, n.1-2, p.64-72, 2010.

QIU, Y.; CHEN, Y.; ZHANG, G.G.Z.; LIU, L.; PORTER, W.R. Developing solid oral dosage forms: pharmaceutical theory and practice. Amsterdam: Elsevier, 2009. 943 p.

SAMAHA, D.; SHEHAYEB, R.; KYRIACOS, S. Modeling and comparison of dissolution profiles of diltiazem modifiedrelease formulations. Diss. Technol., v.16, n.2, p.41-46, 2009 .

SANTOS, H.; VEIGA, F.; PINA, M.; PODEZECK, F.; SOUSA, J. Physical properties of chitosan pellets produced by extrusion-spheronisation: influence of formulation variables. Int. J. Pharm., v.246, n.1-2, p.153-169, 2002.

SOUSA, J.J.; SOUSA, A.; PODCZECK, F.; NEWTON, J.M. Factors influencing the physical characteristics of pellets obtained by extrusion-spheronization. Int. J. Pharm., v.232, n.1-2, p.91-106, 2002.
SREIE, S.; DREU, R.; SIRCA, J.; PINTYE-HODI, K.; BURJAN, T.; PLANINSEK, O. Physicochemical properties of granulating liquids and their influence of microcrystalline cellulose pellets obtained by extrusion-spheronization technology. Int. J. Pharm., v.291, n.1-2, p.1-2, p.99-111, 2005.

UNITED STATES PHARMACOPEIA. 32ed. Rockville: United States Pharmacopeial Convention, 2009. 1391 p.

WLOSNEWSKI, J.C.; KUMPUGDEE-VOLLRATH, M.; SRIAMORNSAK, P. Effect of drying technique and disintegrant on physical properties and drug release behavior of microcrystalline cellulose-based pellets prepared by extrusion/spheronization. Chem. Eng. Res. Des., v.88, n.1, p.100-108, 2010.

YU, L.X.; WANG, J.T.; HUSSAIN, A.S. Evaluation of USP apparatus 3 for dissolution testing of immediate-release products. AAPSPharmSci., v.4, n.1, p.1-5, 2002.

Received for publication on $24^{\text {th }}$ January 2012 Accepted for publication on $29^{\text {th }}$ May 2012 